\title{
ESTUDO ESTEREOLÓGICO DAS CÉLULAS DE PURKINJE CEREBELARES SUBMETIDAS À INTOXICAÇÃO ALCOÓLICA EM RATOS WISTAR
}

\author{
Mara Ibis Rodrigues Apfel ${ }^{1}$, Charles Alfred Ésberard ${ }^{2}$, Fabrício Kafury Pereira Rodrigues ${ }^{3}$, \\ Fayez Mohamad Bahamad Júnior ${ }^{3}$, Rafael Oliveira Sillero ${ }^{3}$
}

\begin{abstract}
RESUMO - Motivo do estudo: Analisar o efeito do álcool sobre as células de Purkinje de ratos. Método: Ratos Wistar receberam oralmente soluções alcoólicas em diferentes concentrações $4 \%, 12 \%$ e $24 \%$. Os animais foram sacrificados com 4, 8 e 12 semanas e os cerebelos foram clivados em cortes aleatórios e uniformemente isotrópicos e incluídos em parafina. Cortes de $6 \mu \mathrm{m}(\mathrm{H} \& \mathrm{E})$ foram analisados por estereologia. Resultados: As diferenças entre a densidade por área e densidade de superfície das células de Purkinje de todos os grupos experimentais $(\mathrm{E})$ e os respectivos controles $(\mathrm{C})$ foram significativas. Com 12 semanas, a densidade volumétrica da célula de Purkinje diminuiu entre os grupos C e E nas concentrações de $4 \%$ e 12\%, mas não para a concentração de $24 \%$, provavelmente devido a menor ingestão de líquido pelos animais. Conclusão: 0 álcool exerceu efeito tóxico sobre o corpo celular da célula de Purkinje nas três concentrações estudadas a partir de 4 semanas.
\end{abstract}

PALAVRAS-CHAVE: cerebelo, estereologia, intoxicação alcoólica, célula de Purkinje.

\begin{abstract}
Stereologic study of the cerebellar Purkinje cells submitted to alcoholic intoxication in Wistar rats
ABSTRACT - Background: to analyze the effect of the alcohol on the cells of Purkinje. Method: Wistar rats received alcoholic solutions orally in different concentrations $4 \%, 12 \%$ and $24 \%$. The animals were sacrificed with 4, 8 and 12 weeks and the cerebella were randomly cut and embedded in paraffin. Sections of $6 \mu \mathrm{m}$ (H\&E) were stereologically analyzed. Results: The differences among the density for area and density of surface of the cells of Purkinje of all of the experimental groups (E) and the respective controls (C) were significant. With 12 weeks the cell of Purkinje volume density decreased among the groups $C$ and $E$ in the concentrations of $4 \%$ and $12 \%$, but not for the concentration of $24 \%$, probably due to smaller liquid ingestion by the animals. Conclusion: The alcohol has toxic effect on the Purkinje cellular body in the three studied concentrations from 4 weeks.
\end{abstract}

KEY WORDS: cerebellum, Purkinje cell, alcohol, stereology.

As células de Purkinje pertencem filogeneticamente ao neocórtex cerebelar, evolutivamente a região mais recente e com uma citoarquitetura caracterizada por três camadas: molecular, Purkinje e granular $^{1-3}$. A célula de Purkinje éo elemento dominante do processo de informação cerebelar e pode apresentar alterações degenerativas na senescência que podem ser notadas por métodos de coloração sim-

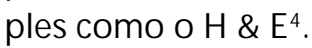

A ingestão crônica de álcool leva a doenças sociais e degenerativas de importância. Em animais, no estado de jejum, 30 minutos após a ingestão de álcool já ocorreu a absorção pelo trato digestivo com níveis sanguíneos altos; mais de $90 \%$ do álcool absorvido é oxidado no fígado e o restante excretado pelos pulmões erins. O consumo crônico pode levar a tolerância e dependência, a graves distúrbios neurológicos e mentais, muitas vezes com decréscimo

\footnotetext{
1Professor Adjunto de Histologia, Laboratório de Histologia e Embriologia, Departamento de Histologia e Embriologia, Instituto de Biologia Roberto Alcântara Gomes, Universidade Estadual do Rio de Janeiro (UERJ) Rio de Janeiro RJ, Brasil e Professor Titular do Laboratório de Histologia, Departamento de Ciências Morfofisiológicas, Faculdade de Medicina de Petrópolis, Fundação Octacílio Gualberto, Petrópolis RJ, Brasil (FMP); ${ }^{2}$ Professor Titular de Fisiologia, Laboratório de Fisiologia, Departamento de Ciências Morfofisiológicas, FMP e do Laboratório de Fisiologia, Departamento de Fisiologia, Universidade Federal Fluminense (UFF), Niterói RJ, Brasil, e do Laboratório do Departamento de Ciências Fisiológicas da Uni-Rio, Professor Emérito da UFES; ${ }^{3}$ nnterno e Estagiário de Pesquisa da Faculdade de Medicina de Petrópolis, Fundação Octacílio Gualberto, Petrópolis RJ, Brasil. Trabalho apoiado pela Faperj (Proc. N E-26 / 171.960/00). Projeto integrado IBRAG/UERJ e FMP/FOG.
}

Recebido 8 Agosto 2001, recebido na forma final 10 Outubro 2001. Aceito 20 Outubro 2001.

Dra. Mara I.R. Apfel - Laboratório de Histologia do DHE - IBRAG -UERJ - R. Professor Manoel de Abreu 444 (antigo 48) / $3^{\circ}$ Andar 20550-170 Rio de Janeiro RJ - Brasil.E-mail maraibis@uerj.br 
das células cerebrais e cerebelares em humanos e animais ${ }^{5-16}$. Em ratos recém-nascidos que receberam cronicamente álcool por via aérea foi observado que as células-alvo foram as de Purkinje que diminuíram em número; depois foram atingidas as células granulares ${ }^{17}$.

O efeito do etanol por via oral (8.1\% etanol v/v) sobre neurônios do hipocampo dorsal de ratas grávidas, durante 10-21 dias de gestação, foi estudado por Barnes e Walker ${ }^{18}$. Estes autores encontraram evidente diminuição de células piramidais (20\%) nas crias. No entanto, não observaram alteração nas células granulares, nem no crescimento físico do animal, sugerindo que os neurônios eferentes são particularmente sensíveis aos efeitos do etanol.

Segundo Pierce e colaboradores ${ }^{15}$, a exposição ao etanol causa direta toxicidade neuronal, especialmente durante períodos de maior vulnerabilidade. Isto está demonstrado em inúmeros estudos nos últimos 20 anos em ratos recém-nascidos, período de maior crescimento cerebelar (período pós-natal entre os dias 4 a 6). Segundo estes autores, o dia inicial da exposição ea duração da exposição não foram identificados como variáveis críticas para a toxicidade. Clos e colaboradores ${ }^{19}$ estudaram o efeito da desnutrição materna de ratas ( $50 \%$ da quantidade diária normal) sobre ratos recém-nascidos de 10, 14 e 21 dias. Observaram que não houve alteração no número das células de Purkinje; no entanto, houve redução das células granulares e em cesto (13\%) e das gliais (44\%).

Há poucos estudos descrevendo alterações neuronais no cérebro e cerebelo de ratos adultos jovens. Gonzalez-Maciel e colaboradore ${ }^{20}$ encontraram diminuição de células de Purkinje cerebelar em ratos de 45 dias de idade alcoolizados (grupo experimental que recebeu ração convencional e mistura águaálcool) durante 90, 120 e 180 dias. Estes autores observaram um grande número de células de Purkinje com citoplasma hipercromático e sem morfologia celular definida, denotando sinais de degeneração celular. Os autores não encontraram estas alterações no grupo controle tradicional (alimentados com ração eágua à vontade) e no grupo controle equienergético (que recebeu ração eágua-açúcar). Armstrong e Schild ${ }^{21}$ fizeram estudo quantitativo de células de Purkinje no cerebelo de ratos albinos, utilizando técnica que hoje é considerada com viés. Estudaram o pregueamento das folhas cerebelares em duas dimensões, estimando o número total de células de Purkinje que ficou em 3,2-3,6 x $10^{5}$ células. As limitações deste método de contagem têm sido amplamente discutidas.

Pretende-se aplicar técnicas estereológicas sem viés para efetuar a quantificação das células de Purkinje cerebelares ${ }^{22-24}$. Segundo Mandarim-deLacerda22, este método provê informações sobre o crescimento (em tumores, em caso de neovascularização) e relações funcionais (alterações na membrana alvéolo-capilar, por exemplo), usando parâmetros relativos e absolutos. Os valores relativos de V (densidade de volume), $\mathrm{S}$ (densidade de superfície) e $\mathrm{N}_{\mathrm{A}}$ (densidade numérica no plano) foram utilizados por nós neste estudo. As células de Purkinje foram escoIhidas para serem estudadas por serem as que em conjunto formam o único sistema eferente cerebelar, funcionando como moduladoras das informações aferentes que chegam ao córtex cerebelar ${ }^{17}$. Estas células fazem a integração neuronal de todas as informações recebidas pelo corpo e controlam os movimentos musculares corporais, sendo frequentemente afetado quando do uso das chamadas bebidas sociais.

\section{MÉTODO}

Modelo experimental

Sessenta ratos Wistar, machos, pesando entre 200$300 \mathrm{~g}$, adultos jovens, foram obtidos do biotério da Fiocruz/ $\mathrm{RJ}$ e submetidos à dieta padrão Nuvilab ${ }^{\circledR}$ para ratos $\mathrm{e}$ água à vontade.

Tabela 1. Distribuição dos animais nos grupos de estudo,em relação aos tempos de administração das soluções alcoólicas em água e suas diferentes concentrações (em \%).

\begin{tabular}{lcccc}
\hline Grupo & 4 semanas & 8 semanas & 12 semanas & Total \\
\hline Controle & 5 & 5 & 5 & 15 \\
Experimental & & & & \\
$4 \%$ & 5 & 5 & 5 & 15 \\
$12 \%$ & 5 & 5 & 5 & 15 \\
$24 \%$ & 5 & 5 & 5 & 15 \\
Total & 20 & 20 & 20 & 60 \\
\hline
\end{tabular}


Estes animais foram divididos em dois grupos: controle (C) e experimental (E), subdivididos em três subgrupos que foram estudados em tempos diferentes: 4, 8 e 12 semanas. A composição das amostras é referida na Tabela 1.

A curva de ingestão total de solução alcoólica em água foi feita para todos os grupos; este consumo foi anotado em dias alternados quando era substituída a solução. O somatório dos volumes ingeridos foi computado como consumo total.

\section{Processamento do material}

Nos tempos previamente determinados, os animais foram anestesiados com Thiopental sódico $(1 \mathrm{mg} / \mathrm{kg}$ ) para proporcionar menor sofrimento possível e, a seguir, craniotomizados Os cerebelos foram retirados após perfusão cardíaca com formol $10 \%$ tamponado em tampão fosfato pH 7,2 por 10 minutos. Cada hemisfério cerebelar (neocórtex cerebelar) foi fragmentado em cortes aleatórios e uniformemente isotrópicos (técnica do orientator) ${ }^{23}$, pós-fixados em formol tamponado por imersão por 48 horas, e processados rotineiramente (lavagem em água corrente, desidratação em álcool, inclusão em xilol e inclusão em parafina).

\section{Estereologia}

Cortes com $6 \mu \mathrm{m}$ de espessura, obtidos a partir dos blocos, foram corados por hematoxilina e eosina. Para contagem estereológica foi utilizado o sistema teste M42 que utiliza um conjunto de linhas e pontos que ficam superpostos à imagem morfológica. As características deste sistema-teste são: calibração $(d$, comprimento das linhas curtas), área-teste $\left(A_{T}, 36,36 d^{2}\right)$, linha-teste $\left(L_{T}, 21 d\right)$, pontos-teste ( $\mathrm{Pp}, 42)$.

Foram determinados os seguintes parâmetros estereológicos nas células de Purkinje cerebelares ${ }^{22}$ :

a) Densidade de volume (Vv):

$V_{V}=\frac{P_{P}}{P_{T}}(\%)$, sendo $P_{P}$ o número de pontos contados sobre as células de Purkinje e $\mathrm{P}_{\mathrm{T}}$ o número total de pontos-teste.

b) Densidade de superfície (Sv):

$S_{V}=\frac{2 . l}{L_{T}}\left(\mathrm{~mm}^{2} / \mathrm{mm}^{3}\right)$, sendo I o número de intersecções dos perfis celulares com a linha-teste $\left(L_{T}\right)$.

c) Densidade por área $\left(\mathrm{N}_{\mathrm{A}}\right)$ :

$N_{A}=\frac{N}{A_{T}}\left(1 / \mathrm{mm}^{3}\right)$, sendo $\mathrm{N}$ o número de perfis celulares observados na área-teste $\left(A_{T}\right)$.

As diferenças entre os grupos foram testadas usando o teste não paramétrico de Kruskal-Wallis, seguido do teste de Mann-Whitney para testar, dois a dois, os grupos onde houve diferença. Foi considerado significativo o índice de significância de 0,05.

\section{RESULTADOS}

Os resultados estão apresentados na Tabela 2 ena Figura 1. A Tabela 2 indica o resultado estereológico encontrado nos diferentes grupos. Com quatro semanas de administração de solução alcoólica em água, em todas as concentrações utilizadas, os parâmetros determinados para a célula de Purkinje diminuíram significativamente em comparação ao grupo controle. Na concentração de $4 \%$ houve diminuição de $56 \%$ do $\mathrm{Vv}, 44 \%$ deSve $37 \% \mathrm{~N}_{\mathrm{A}}$. Com oito semanas de administração, em todas as concentrações utiliza-

Tabela 2. Média $\pm D P$ dos valores estereológicos determinados para os diferentes grupos de animais.

\begin{tabular}{|c|c|c|c|c|}
\hline Código & Grupo & $\mathrm{Vv}$ & Sv & $\mathrm{N}_{\mathrm{A}}$ \\
\hline & 4 Semanas & & & \\
\hline 1 & Controle & $2,3 \pm 0,6$ & $5,4 \pm 1,3$ & $122,5 \pm 11,7$ \\
\hline 4 & $4 \%$ & $1,0 \pm 0,3$ & $3,6 \pm 0,5$ & $76,7 \pm 10,1$ \\
\hline 7 & $12 \%$ & $1,0 \pm 0,3$ & $3,6 \pm 1,0$ & $71,6 \pm 4,7$ \\
\hline \multirow[t]{2}{*}{10} & $24 \%$ & $0,7 \pm 0,2$ & $2,9 \pm 0,6$ & $67,0 \pm 7,2$ \\
\hline & 8 Semanas & & & \\
\hline 2 & Controle & $2,3 \pm 0,6$ & $5,4 \pm 1,3$ & $122,5 \pm 11,7$ \\
\hline 5 & $4 \%$ & $1,0 \pm 0,3$ & $3,5 \pm 0,9$ & $81,9 \pm 21,2$ \\
\hline 8 & $12 \%$ & $0,8 \pm 0,2$ & $2,9 \pm 1,1$ & $71,4 \pm 17,7$ \\
\hline \multirow[t]{2}{*}{11} & $24 \%$ & $1,0 \pm 0,4$ & $3,2 \pm 0,8$ & $83,9 \pm 17,7$ \\
\hline & 12 Semanas & & & \\
\hline 3 & Controle & $2,4 \pm 0,6$ & $5,2 \pm 1,2$ & $120,0 \pm 13,5$ \\
\hline 6 & $4 \%$ & $0,9 \pm 0,6$ & $3,1 \pm 0,8$ & $81,7 \pm 11,4$ \\
\hline 9 & $12 \%$ & $1,2 \pm 0,4$ & $4,0 \pm 1,1$ & $80,9 \pm 23,1$ \\
\hline 12 & $24 \%$ & $1,6 \pm 0,3$ & $4,5 \pm 1,3$ & $96,2 \pm 18,4$ \\
\hline
\end{tabular}

Comparações

$1 \times 4$
$1 \times 7$
$1 \times 10$
$4 \times 7$
$4 \times 10$
$7 \times 10$
$2 \times 5$
$2 \times 8$
$2 \times 11$
$5 \times 8$
$5 \times 11$
$8 \times 11$
$3 \times 6$
$3 \times 9$
$3 \times 12$
$6 \times 9$
$6 \times 12$
$9 \times 12$

Teste de Mann-Whitney

$\begin{array}{ccc}0,008 & 0,02 & 0,008 \\ 0,008 & 0,05 & 0,008 \\ 0,008 & 0,008 & 0,008 \\ \text { NS } & \text { NS } & \text { NS } \\ 0,05 & 0,05 & \text { NS } \\ \text { NS } & \text { NS } & \text { NS } \\ 0,008 & 0,05 & 0,008 \\ 0,008 & 0,008 & 0,008 \\ 0,008 & 0,02 & 0,008 \\ \text { NS } & \text { NS } & \text { NS } \\ \text { NS } & \text { NS } & \text { NS } \\ \text { NS } & \text { NS } & \text { NS } \\ 0,008 & 0,02 & 0,008 \\ 0,008 & \text { NS } & 0,05 \\ \text { NS } & \text { NS } & 0,05 \\ \text { NS } & \text { NS } & \text { NS } \\ 0,03 & \text { NS } & \text { NS } \\ \text { NS } & \text { NS } & \text { NS }\end{array}$

As diferenças entre os grupos (apresentados com os códigos indicados na tabela) foram testados com o teste não paramétrico de Mann-Whitney. 


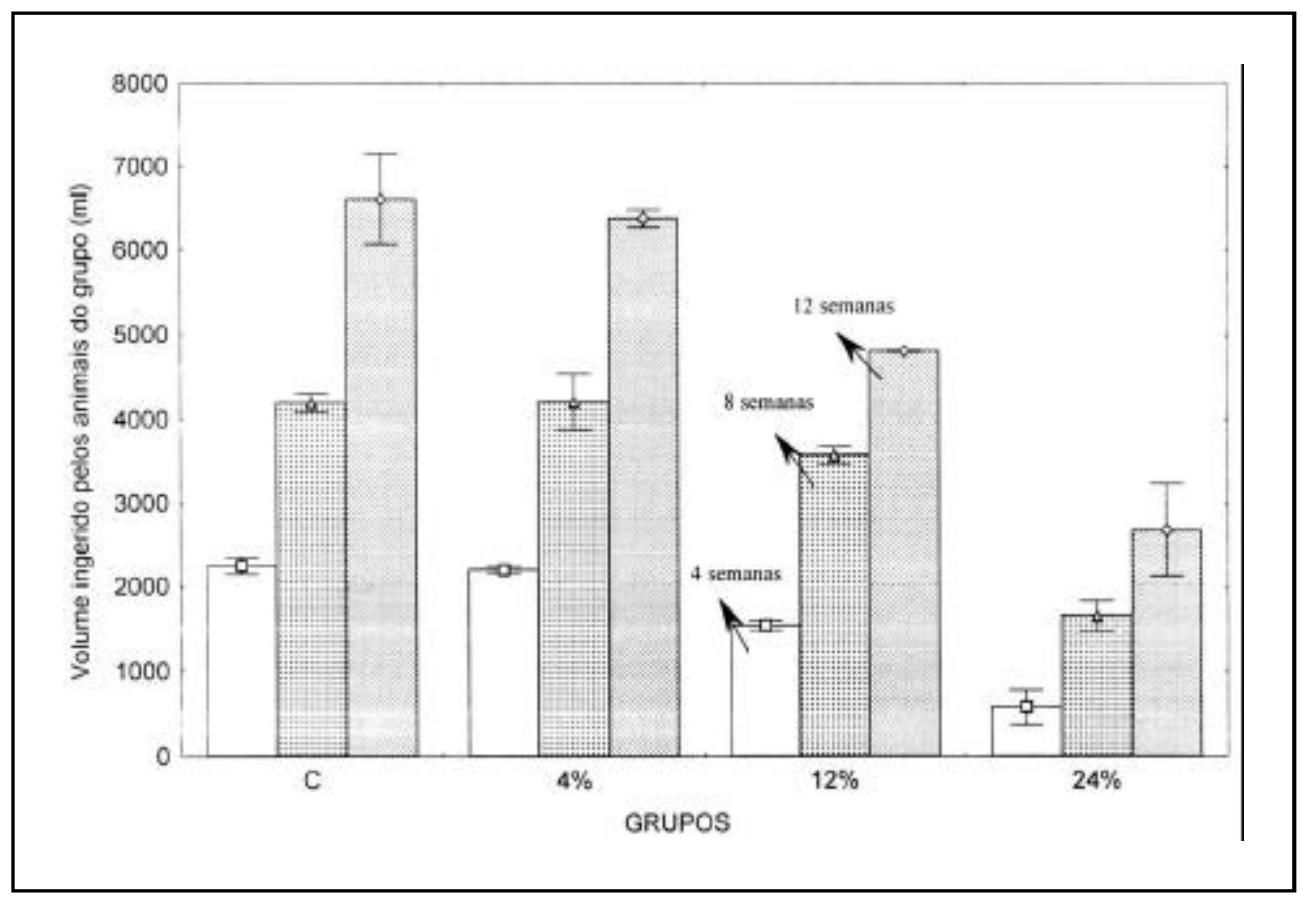

Fig 1. Gráfico em barras do volume total ingerido por cada grupo de animais: controle (água), grupos experimentais (solução alcoólica em água) em cada um dos tempos analisados.

das, o VV, Sve o $\mathrm{N}_{\mathrm{A}}$ diminuíram significativamenteentre o controle e os grupos experimentais. Na menor concentração de $4 \%$ em relação ao controle, houve uma diminuição de $56 \%$, 35\% e 33\%, respectivamente. Houve, então, manutenção dos danos celulares que já tinham ocorrido no tempo de quatro semanas.

Com 12 semanas de administração, o Vv, Sv e o $\mathrm{N}_{\mathrm{A}}$ da célula de Purkinje diminuíram significativamente na comparação entre os grupos controle e os experimentais. Na menor concentração, $4 \%$, em relação ao grupo controle, houve diminuição de $63 \%$, $40 \%$ e $32 \%$, respectivamente. Houve, portanto, manutenção dos danos celulares que já tinham ocorrido no tempo de quatro semanas.

Em quatro semanas, todas as diferenças no Sv, $V \vee$ e $\mathrm{N}_{\mathrm{A}}$ foram significativas na comparação entre o grupo controle e os demais grupos experimentais, demonstrando que os corpos celulares de Purkinje tiveram diminuição das densidades de superfície, volume e número em todas as concentrações. Com o tempo de 12 semanas, as diferenças do Sv foram significativas somente entre o grupo controle e a menor concentração de solução alcoólica em água (4\%); as diferenças do $\mathrm{Vv}_{\mathrm{V}} \mathrm{N}_{\mathrm{A}}$ entre o grupo controle e os grupos experimentais foram significativos.

A Figura 1 mostra que os animais dos grupos experimentais ingeriram volumes diferentes da solução alcoólica; os do grupo de concentração de 4\% tiveram ingestão muito similar ao grupo controle.

\section{DISCUSSÃO}

Numerosos estudos vêm fornecendo dados sobre a fina estrutura e organização do cérebro e cerebelo em mamíferos, em especial sobre as células granulares e de Purkinje do cerebelo humano e de animais ${ }^{5,6,11,14,15,25-27}$. Bauer-Moffett e Altman ${ }^{17}$ utilizaram grandes concentrações de álcool inalado $(239 \mathrm{mg} / 100 \mathrm{ml}$ ) em ratos recém-nascidos (3 a 20 dias) sabidamente mais susceptíveis a intoxicação alcoólica. Nestes animais, o crescimento corporal foi alterado e o crescimento do cerebelo foi inibido mais de duas vezes que o resto do cérebro. Ao microscópio óptico, eles observaram que das duas populações celulares maiores do cerebelo - Purkinje e granular - as primeiras foram afetadas precocemente após dois dias de tratamento.

Pouco se sabe sobre as alterações morfológicas do corpo celular das células de Purkinje no neocerebelo de ratos adultos que tenham sido submetidos à influência tóxica do álcool em concentrações semelhantes às usadas socialmente, utilizando a nova estereologia. No presente trabalho, estudou-se ratos adultos jovens submetidos a diferentes concentrações de álcool, sendo a maior de $24 \%$, que corresponde ao grupo de bebidas de maior teor alcoólico, como a vodka.

Após quatro semanas de exposição a solução alcoólica em água, já encontrou-se alterações nas célu- 
las de Purkinje do neocórtex cerebelar, mesmo na concentração mais baixa (4\%). Provavelmente esta concentração causou toxicidade devido ao fato da entrada do etanol no sistema nervoso ser livre, ou seja, não há limite para a passagem do álcool pela barreira hematoencefálica devido à sua alta lipossolubilidade. De acordo com Falavigna e colaboradores ${ }^{7}$ logo após a sua ingestão a concentração de etanol no cérebro quase se iguala à da concentração sanguínea.

$\mathrm{Na}$ intoxicação aguda com ingestão excessiva ocorrem sinais de depressão no SNC com deterioração das funções vestibular e cerebelar com surgimento de sintomas como ataxia severa e nistagmo. Na intoxicação crônica podem ocorrer complicações como a da síndrome de Wernick- Korsakoff, que é uma doença aguda, desmielinizante, dealta incidência em etilistas crônicos, ou ainda degeneração cerebelar com perda das células de Purkinje. Acredita-se que o etanol tenha uma ação neurotóxica direta, causando atrofia cerebral e síndrome amnésica7.

No consumo crônico e excessivo, porém intermitente, há uma queda no metabolismo pela ausência (fase de abstinência) desta droga rica em energia, contribuindo para a toxicidade orgânica assim como para deficiências nutricionais que podem acompanhá-la. A dose, o grau e a duração do consumo determinam os sintomas da síndrome de abstinência. No consumo crônico e continuado de álcool em altas doses por um longo período ocorre tolerância e dependência física, processo complexo que inclui alterações degenerativas do SNC devido a neurotoxicidade, no qual a capacidade de metabolizar drogas aumenta. No entanto, por ser uma droga sedativahipnótica, há um limite para esta tolerância, podendo levar a letalidade ${ }^{28}$.

Utilizando a análise quantitativa preconizada por Mandarim-de-Lacerda ${ }^{22}$, analisamos uma característica marcante: tamanho do corpo celular no arranjo em camada única descontínua. Comparando o $\mathrm{N}_{\mathrm{A}(\text { Purkinje) }}$ eS $\mathrm{S}_{\mathrm{V}(\text { Purkinje) }}$ dos grupos controle e experimentais de 4, 8 e 12 semanas notamos que todas as diferenças entre o controle e os três grupos experimentais foram significativas. Com 12 semanas o $\mathrm{V}_{\mathrm{V}(\text { (Purkinje) }}$ diminuiu significativamente entre os grupos controle e experimentais nas concentrações de $4 \%$ e $12 \%$. Entretanto, a diminuição do $V_{v(\text { Purkinje) }}$ na concentração de $24 \%$, que era esperada, não foi significativa provavelmente pelo fato destes animais terem apresentado menor ingestão da solução alcoólica em água.
Utilizamos a combinação inclusão em parafina e coloração pelo $\mathrm{H}-\mathrm{E}$, conforme usado por diferentes autores $^{3,5}$. Palkovits e colaboradores ${ }^{3}$ fizeram a análise quantitativa de cerebelo de gatos usando duas dimensões, utilizando três processamentos histológicos diferentes e observaram que a combinação da inclusão em parafina e coloração por H-E dava resultados intermediários entre a melhor combinação (Durcupan-azul de metileno) e a pior combinação (parafina-método de Cajal). Armstrong e Schild ${ }^{21}$ também utilizaram a bidimensão e estimaram o número total das células de Purkinje de cerebelo de ratos jovens ( 70 dias) albinos em $3,3 \times 10^{5} \pm 0,2 \times 10^{5}$ células (média $\pm D P$ ). Entretanto, não fizeram a determinação das densidades da célula de Purkinje, conforme determinado no presente trabalho.

A solução alcoólica em água administrada por via oral a ratos adultos demonstrou ser tóxica diretamente sobre as células de Purkinje, em todas as concentrações estudadas. Este pensamento provavelmente deve estar correto quando comparamos o presente estudo com o realizado em ratos sob intoxicação alcoólica utilizando controle que receberam dieta com água ou água-açúcar. O efeito tóxico direto foi comprovado, pois o grupo que recebeu dieta equienergética com açúcar não apresentou redução do número de células de Purkinje, descartando a possibilidade da concentração de açúcar do álcool poder influenciar neste efeito tóxico ${ }^{20}$.

Segundo Pierce e colaboradores ${ }^{15}$ parece que a concentração de álcool (teor alcoólico da bebida ingerida socialmente) é muito importante, e não o dia inicial da exposição e a duração da exposição. Estas duas últimas variáveis não foram identificadas como críticas após a extensa revisão dos últimos 20 anos feita por estes autores. O presente trabalho observou que o volume ingerido, além da concentração utilizada, foi muito importante nas alterações degenerativas da célula de Purkinje, embora o tempo de exposição crônica não tenha influenciado os resultados.

As células de Purkinje se apresentaram por vezes com o corpo celular hipercromático e núcleo bem corado, ou corpo celular com cromatólise sem morfologia definida, consideradas alterações degenerativas. Este resultado está de acordo com o de Gonzalez-Maciel e colaboradores ${ }^{20}$. Estes pesquisadores demonstraram alterações morfológicas no corpo celular em ratos alcoolizados, machos, recém-nascidos, e afirmaram tratar-se de sinais degenerativos, enquanto os controles não-alcoolizados (normal e sob dieta equienergética) não apresentaram estas 
alterações. Tabbaa e colaboradores ${ }^{16}$ tentaram determinar se a destruição dos dendritos das células dePurkinje indicaria diminuição do "input" sináptico sobre estas células em ratos idosos F344 alimentados cronicamente com álcool. Não encontraram alterações significativas no número das células granulares e dendritos das células de Purkinje, utilizando a estereologia (método do "optical fractionator").

Em conclusão, acreditamos que o presente estudo enfocando o corpo celular das células de Purkinje quanto à densidade numérica, densidade de volume e densidade de superfície acrescente dados importantes para melhor análise dos efeitos biológicos do álcool no sistema nervoso. A administração oral ecrônica de solução alcoólica em água, nas concentrações de 4, 12 e 24\%, causa alterações morfológicas no corpo celular das células de Purkinje do neocórtex cerebelar de ratos adultos a partir de 4 semanas.

Agradecimentos - Os autores agradecem ao Prof. Dr. Carlos Alberto Mandarim-de-Lacerda pelo suporte científico e treinamento prático dos estagiários de pesquisa durante a análise estereológica, sem o qual este trabalho não seria possível.

\section{REFERÊNCIAS}

1. Crossman AR, Neary D. Neuroanatomia. Rio de Janeiro: Guanabara Koogan, 1997.

2. Hámori J, Szentágothai J. Identification under the electron microscope of climbing fibers and their synaptic contacts. Exper Brain Rev 1996;1: 65-81.

3. Palkovits M, Magyar P, J Szentágotahi.Quantitative histological analysis of the cerebellar cortex in the cat. II. Cell numbers and densities in the granular layer. Brain Res 1971;32:15-30.

4. Rogers J, Zornetzer SF, Bloom FE, Ronal EM. Senescent microstructural changes in rat cerebellum. Brain Res 1984;292:23-32.

5. Chen W-J A, Parnell SE, Wets JR. Early posnatal alcohol exposure produced long-term deficits in brain weigh, but not the number of neurons in the locus coeruleus. Develop Brain Res 1999;118:33-38.

6. Dlugos CA, Pentney RJ. Morphometric evidence that the total number of synapses on Purkinje neurons of old F344 rats is reduced after onterm ethanol treatment and restored to control levels after recovery. Alcohol 1997;32:161-172.

7. Falavigna A,Segatto ACF, Wie C, Slompo MA. Etanol e sistema nervoso. Rev Cient AMECS 1998;7:27-34
8. Goodlett CR, Eilers AT. Alcohol-induced Purkinje cell loss with a single binge exposure in neonatal rats: a stereological study of temporal windows of vulnerability. Alcohol Clin Exp Res 1997;21:738-744.

9. Goodlett CR, Peterson SD, Lundahl KR, Pearlman AD. Binge-like alcohol exposure of neonatal rats via intragastric intubation induces both Purkinje cell loss and cortical astrogliosis. Alcohol Clin Exp Res 1997;21:1010-1017.

10. Gross MM. Alcohol intoxication and withdrawal. Advances in experimental medicine and biology. New York: Plenum Press, 1977.

11. Karhunen PJ, Erkinjuntii T, Laippala P. Moderate alcohol consumption and loss of cerebelar Purkinje cells. Br Med J 1994;308:1663-1667.

12. Kornstein MA, Lieber CS. Medical complications of alcoholism. In Meldelson JH, Meloo NK (eds). The diagnosis and treatment of alcoholism. New York: MacGrw-Hill, 1985:21-24.

13. Majchrowicz E, Noble W. Biochemistry and pharmacology of ethanol. New York: Plenum Press, 1979.

14. Pentney RJ. Measurements of dendritic path lengths provide evidence that ethanol-induced lengthening of terminal dendritic segments may result from dendritic regression. Alcohol 1995;30:87-96

15. Pierce DR, Williams DK, Light KE. Purkinje cell vulnerability to developmental ethanol exposure in the rat cerebellum. Alcohol Clin Exp Res 1999;23:1650-1659.

16. Tabbaa S, Dlugos CA, Pentney RJ. The number of granule cells and spine density on Purkinje cells in aged, ethanol-fed rats. Alcohol 1999;17:253-260

17. Bauer-Moffett C, Altman J. The effect of ethanol chronically administrered to preweanling rats on cerebellar development: a morphological study. Brain Res 1977;119:249-268.

18. Barnes DE, Walker DW. Prenatal ethanol exposure permanently reduces the number of pyramidal neurons in rat hippocampus. Dev Brain Res 1981;1:333-340

19. Clos J, Favre C, Selme-Matrat M, Legrand J. Effects of undernutrition on cell formation in the rat brain and specially on cellular composition of the cerebellum. Brain Res 1977;123:13-26.

20. Gonzalez-Maciel A, Romero-Velazquez RM, Hernandez-Islas JL, SiciliaArgumeddo G, Fragoso-Soriano R, Cravioto J. Purkinje cell density in cerebella of alcoholized and non-alcoholized male rat offspring. Arch Med Res 1994;25: 427-434.

21. Armstrong DM, Schild RF. A quantitative study of the Purkinje cells in the cerebellum of the albino rat. J Comp Neurol $1970 ; 139: 449-456$.

22. Mandarim-de-Lacerda CA. Stereology in the normal and pathological morphologic research. Biom Res 1998; 9:153-163.

23. Mattfeldt T, Mobius HJ, Mall G. Orthogonal triplet probes: an efficient method for unbiased estimation of length and surface of objects with unknown orientation in space. J Microscop 1995;139:279-289.

24. Howard CV, Reed MG. Unbiased stereology: three-dimensional measurement in microscopy. Oxford: Springer, 1998:246.

25. Pakkenberg B, Gundersen HJG. Total number of neurons and glial cells in human brain nuclei estimated by disector and the fractionator. J Microsc 1988;150:1-20.

26. West MJ, Gundersen HJG. Unbiased stereological estimation of the number of neurons in the human hippocampus. J Comp Neurol 1990;296:1-22.

27. West MJ, Slomianka L, Gundersen HJG. Unbiased stereological estimation of the number of neurons in the subdivisions of the rat hippocampus using the optical fractionator. Anat Rec 1991;231:482-497.

28. Katzung BG. Basic \& clinical pharmacology. 7.Ed. Stamford: Appleton \& Lange 1998:375-376. 